\title{
ĐÁNH GIÁ HỌC SINH TIỂU HỌC THEO HƯớNG TIẾP CẬN NĂNG LỰC
}

\section{Assessing primary students based on approaching competency}

PGS.TS. Trần Ngọc Lan*

\section{TÓM TẮT}

Vấn đề có tính thời sụ và cấp bách đặt ra trong tất cả các cuộc hội thảo gần đây về đổi căn bản toàn diện quá trình dạy hoc, đó là tiêu chí đánh giá họ sinh khi chuyển tù huoóng tiếp cận nội dung sang huớng tiếp cận năng lục; chuyển tù quá trình dạy học sang quá trình tụ học; tụ giáo dục nhu thế nào. Rất nhiều câu hỏi được đạt ra tù các cấp độ: Người quản lý; người trục tiếp giảng dạy; người nghiên cúu giáo dục; phụ huynh và người học. Với các yêu cầu bức thiết hiện nay, xu huớng đánh giá cần phát huy tốt 3 chức năng quan trọng đó là : chức năng điều khiển, điều chỉnh quá trình dạy học; chức năng phát triển và chức năng giáo dục. Muốn vâyy cần tập trung vào hai phương diện: Đánh giá về phẩm chất và đánh giá về năng lực thông qua việc đánh giá sản phẩm của các hoạt động hình thành kiến thức và rèn luyện kỹ năng theo chuẩn của tùng môn học và các hoạt động giáo dục cu thể.

Tù̀ khoá: đánh giá, học sinh tiểu học, tiếp cận năng lục, tụ học, tụ giáo dục.

\begin{abstract}
In recent educational conferences, current an urgent issue regarding comprehensive teaching process is seriously discussed. These are criteria to assess students when shifting from contentbased approach to competent-based approach; shifting from teaching process to self-study process; and how to self educate. There have many questions with different objectives such as: administrator, teachers, educational researchers, parents and learners. With urgent needs today, the trend of assessment needs to well develop three crucial functions, these are: operating and adjusting functions in teaching processs, development function and educational function. Therefore, in order to do that, it needs to focus on two aspects: assessing of virtue and assessing of competency through assessment of products in activities of knowledge forming and training skills based on standards of each subject and each specific educational activity.
\end{abstract}

Keywords: assessment, primary students, competent-based approach, self-study, self-education

\section{Quan niệm chung về đánh giá học sinh theo hướng tiếp cận năng lực}

\subsection{Quan niệm về vai trò}

Chúng ta đều biết rằng bất cứ một quy trình công nghệ sản xuất một sản phẩm nào thì khâu đánh giá, kiếm định chất lượng đầu ra cho mỗi sản phẩm, nhằm xác định giá trị đóng góp của sản phẩm trong đời sống xã hội có tính chất quyết định sự thành công hoặc thất bại của quy trình sản xuất đó. Quan niệm hiện đại khẳng định sản phẩm của quá trình dạy học và giáo dục chính là con người; điều này cho thấy ý nghĩa tối quan trọng của khâu đánh giá kiểm định chất lượng đầu ra trong mỗi giai đoạn và cả quá trình dạy học và giáo dục nói chung. Trong năm thành tố quan trọng

\footnotetext{
* Khoa Giáo dục tiểu học - Đại học Sư phạm Hà Nội
} 
của quá trình dạy học ta thấy rõ kiểm tra, đánh giá là có vai trò then chốt. Thực tế cho thấy nội dung; phương pháp, hình thức kiểm tra đánh giá quyết định nội dung, phương pháp hình thức tổ chức học tập của mỗi cá nhân trong suốt quá trình học tập. Vấn đề cần xác định rõ các giá trị nền tảng cho sự phát triển bền vững lâu dài của một công dân trong xã hội là gì, những phẩm chất nào, năng lực nào và mức độ cần tích lũy tới đâu trong từng giai đoạn của quá trình giáo dục phổ thông. Điều này có ý nghĩa quyết định giúp học sinh sau khi rời ghế nhà trường có được những tri thức tốt cho lao động phổ thông hoặc tiếp tục lĩnh hội tri thức của giáo dục bậc cao? Đây chính là câu hỏi lớn không dễ trả lời đầy đủ trong một bài viết, vì vậy trong phần dưới đây xin trình bày một số vấn đề xung quanh việc đánh giá vì sự phát triển của học sinh tiếu học, trong đó sẽ minh họa cụ thể một số ý qua việc đánh giá sự phát triển năng lực của học sinh về môn Toán.

\subsection{Quan niệm về tiêu chí đánh giá mói}

Vấn đề có tính thời sự và cấp bách đặt ra trong tất cả các cuộc hội thảo gần đây về đổi căn bản toàn diện quá trình dạy học, đó là tiêu chí đánh giá học sinh khi chuyển từ hướng tiếp cận nội dung sang hướng tiếp cận năng lực; chuyển từ quá trình dạy học sang quá trình tự học; tự giáo dục như thế nào? Rất nhiều câu hỏi được đặt ra từ các cấp độ: người quản lý; người trực tiếp giảng dạy; người nghiên cứu giáo dục; phụ huynh và người học. Vậy thì tiêu chí đánh giá mới là gì, các biểu hiện cụ thể các tiêu chí đó trong từng giai đoạn, từng môn học là thế nào? Trong hội thảo (vào trung tuần tháng 5/2013 ở Tam Đảo) về "Tăng cường năng lực quản lý lớp học" thì các thành viên đều nhất trí ý kiến cho rằng yêu cầu mới trong giáo dục và dạy học giai đoạn tới chính là: chuyển từ quá trình Giáo dục thành quá trình tự giáo dục; chuyển từ quá trình dạy của giáo viên thành quá trình tự học của học sinh; chuyển từ hình thức dạy đồng loạt cả lớp sang hình thức tự học theo nhóm; chuyển việc học theo lời thầy nói sang tự học với tài liệu hướng dẫn, tự thực hành trải nghiệm khám phá có sự tương tác cùng bạn bè; học sinh tự quản; tự đánh giá cùng với sự đánh giá của bạn; của thầy; của cha mẹ và cộng đồng. Trong hội thảo quốc gia về xây dựng chương trình giáo dục phổ thông tháng 12/2014 tại Hà Nội, nhiều bài viết của các báo cáo viên đã bàn khá sâu sắc về phát triển năng lực giải quyết vấn đề của học sinh trong quá trình dạy hoc các môn học. Nhìn chung với các yêu cầu bức thiết hiện nay, xu hướng đánh giá cần phát huy tốt 3 chức năng quan trọng đó là: chức năng điều khiển, điều chỉnh quá trình dạy học; chức năng phát triển và chức năng giáo dục. Muốn vậy cần tập trung vào hai phương diện: đánh giá về phẩm chất và đánh giá về năng lực thông qua việc đánh giá sản phẩm của các hoạt động hình thành kiến thức và rèn luyện kỹ năng theo chuẩn của từng môn học và các hoạt động giáo dục cụ thể. Thực chất đánh giá sự tiến bộ của học sinh theo chuẩn kiến thức, kỹ năng của chương trình giáo dục từ đó có những minh chứng cụ thể về sự hình thành và phát triển năng lực chung cũng như đánh giá sự hình thành, phát triển các phẩm chất riêng của mỗi học sinh. Thiết nghĩ nhiệm vụ khó khăn của các nhà quản lý, các nhà nghiên cứu giáo dục trong toàn xã hội hiện nay là xác định các tiêu chí đánh giá thật gọn, thật rõ ràng cụ thể để mỗi học sinh dễ dàng tự kiểm soát các tiêu chí đó với bản thân trước khi nghe các đánh giá từ bạn bè, thầy cô và cha mẹ. Với quan niệm đó, các tiêu chí về năng lực chung chúng tôi thấy cần đặc biệt chú ý tới 3 năng lực cốt lõi nên đánh giá chặt chẽ ngay từ cấp tiểu học là: 1 . Năng lực tự phục vụ; 2. Năng lực hợp tác; 3. Năng lực tự học. Các tiêu chí đánh giá về phẩm chất cũng quan tâm tới 3 tiêu chí cốt lõi: 
1. Chăm chỉ - chuyên cần;

2. Tự trọng - tự tin, tự chịu trách nhiệm;

3. Trung thực - kỷ luật.

\subsection{Nguyên tắc đánh giá}

Để kết quả đánh giá có ý nghĩa thực tiễn và định giá đúng về năng lực và phẩm chất của học sinh, chúng tôi cho rằng cần đảm bảo một số nguyên tắc sau:

* Các nguyên tắc có tính truyền thống:

a. Đảm bảo tính mục tiêu (tính chính xác)

b. Đảm bảo tính khách quan

c. Đảm bảo tính hệ thống, tính toàn diện

d. Đảm bảo tính vừa sức và tính phát triển

e. Đảm bảo tính công khai minh bạch

* Một số nguyên tắc mới cần bổ sung

a. Đảm bảo thực chất, liên tục, nhất quán ở tất cả các cấp học vì sự tiến bộ của học sinh và sự hội nhập toàn cầu.

b. Đa dạng hóa các hình thức đánh giá, đánh giá ngay trong quá trình học tập.

c. Đánh giá theo hướng mở (để học sinh có cơ hội bộc lộ rõ các năng lực tư duy độc lập và các phẩm chất cá biệt, chống học tủ...)

\section{Một số bất cập trong công tác đánh giá học sinh theo hướng tiếp cận năng lực}

Trong các giai đoạn trước đây, việc đánh giá quá trình dạy học và giáo dục cũng đã đạt được những yêu cầu của xã hội đặt ra và đã góp phần đáng kể vào các thành quả mà giáo dục mang lại trong cuộc sống hiện tại. Tuy nhiên để đáp ứng xu hướng toàn cầu hóa như hiện nay và góp phần đổi mới căn bản toàn diện về giáo dục, chúng ta không thể mãi hoài niệm về các thành tích đã có. Điều quan trọng hơn là phải nhìn nhận thấy điều còn chưa tốt trong mối tương quan chung để tiếp tục hoàn thiện. Thực tế cho thấy chất lượng giáo dục phổ thông trong những năm gần đây chưa đáp ứng được yêu cầu của xã hội. Những biểu hiện đa dạng và đáng lo ngại ở học sinh cả hai phương diện năng lực và phẩm chất có ở tất cả các cấp học như: bạo lực trong nhà trường vì sự ganh ghét cá nhân; sự vô cảm, thậm chí đồng lõa của nhiều học sinh trước hành vi thiếu trung thực trong thi cử... Nhiều kết quả đánh giá có độ tin cậy chưa cao... Điều đó cho thấy sự bất cập trong công tác đánh giá phẩm chất và năng lực trong học đường nói riêng và trong giáo dục của toàn xã hội nói chung. Việc quá tải trong công việc và tình trạng chấm bài thiếu phản hồi cụ thể của giáo viên gây ra các phản ứng và suy nghĩ lệch lạc của học sinh còn khá phổ biến. Bệnh "Thành tích" biểu hiện ở nhiều hình thức và cấp độ vì vậy các giải pháp đảm bảo chất lượng còn gặp nhiều khó khăn. Chúng ta nghĩ gì khi Cộng hòa Pháp hàng năm học sinh thường tốt nghiệp phổ thông chỉ đạt khoảng $80 \%$. Nước Mỹ có 26 bang thi tốt nghiêp phổ thông thì cũng không có bang nào học sinh đạt tới tỷ lệ 90\%, trong khi ở nước ta năm (2012 - 2013) đạt tới gần $98 \%$ trong toàn quốc (xem kênh tuyển sinh). Những con số trên cho chúng ta - những người làm công tác giáo dục thông điệp gì, phải 
chăng chúng ta có chất lượng cao hơn cả Pháp và Mỹ? Chúng ta cần có suy nghĩ và hành động gì để từng bước nâng cao độ tin cậy trong công tác đánh giá sự phát triển năng lực và phẩm chất của học $\sinh$ ?

\section{Một số đề xuất bước đầu}

\subsection{Về phwơng diện quản lý và nghiên cúu}

Những bất cập nêu trên đòi hỏi sự góp sức của toàn xã hội trước hết là của các nhà quản lý hoạch định chính sách về giáo dục, các nhà nghiên cứu chương trình giáo dục, các giáo viên và các bậc phụ huynh. Chúng ta cần phải kiên quyết, kiên trì và thẳng thắn chấp nhận thực tiễn trong một thời gian để các tư tưởng đúng, các hoạch định có giá trị đi vào thực tiễn. Theo các văn bản (từ trước tới nay), các tư tưởng, các quan điểm định hướng; các nguyên tắc về đánh giá luôn đúng và phù hợp với các giai đoạn cụ thể, tuy nhiên sự thiếu đồng bộ về nội dung đánh giá, về phương pháp đánh giá về cách thức tổ chức đánh giá đã dẫn tới sự sai lệch về các kết quả đo lường. Chẳng hạn, các nhà quản lý và hoạch định xã hội cần hiểu rõ thực trạng, chỉ ra chỗ thiếu đồng bộ, từ đó có ý kiến chỉ đạo cụ thể sát thực và nhất quán; các chuyên gia cần nghiên cứu đưa ra được các tiêu chí cụ thể, các biểu hiện đặc trưng về các dạng năng lực và phẩm chất, minh họa rõ ở từng môn học và hỗ trợ kỹ thuật để thiết kế các nội dung đánh giá sát mục tiêu; các bộ phận hành chính cần chính xác hóa các văn bản pháp quy... Tránh tình trạng như: nội dung và hình thức đánh giá không tương xứng với các phẩm chất và năng lực muốn đánh giá và không phân hóa được đối tượng học sinh.

\subsection{Về phương diện tổ chức đánh giá}

Tổ chức đánh giá thật nghiêm túc theo chuẩn đã định, không thách đố học sinh, không tạo áp lực đối với học sinh và phụ huynh. Để tổ chức đánh giá cần thiết kế nội dung đánh giá và giải trình được các mục tiêu về năng lực và phẩm chất với mỗi nội dung khi cần thiết. Học sinh đạt tới mức nào trong thang đánh giá (biết; hiểu; vận dụng trực tiếp hoặc vận dụng có sáng tạo linh hoạt...), người tổ chức đánh giá cần phải để nguyên mức đó không điều chỉnh kết quả, không "nuông chiều” theo tâm lý kỳ vọng của phụ huynh (nhất là phụ huynh học sinh tiểu học). Chúng ta cần sử dụng truyền thông để giúp một bộ phận các phu huynh không nhầm lẫn việc đánh giá với việc động viên học tập. Điều này nói thì không khó nhưng để hiện thực hóa thì đây là một bước ngoặt mang tính cách mạng và có vai trò quyết định trong đổi mới quá trình dạy và học. Kỹ năng đưa ra nhận xét sát thực với năng lực và phẩm chất của học sinh là chìa khóa của giáo viên để giải quyết vấn đề này. Kinh nghiệm của một số cơ sở đào tạo dân lập trong nước và quốc tế cho thấy, nếu thực hiện như trên một cách đồng bộ và nhất quán trong một số năm liên tục sẽ cho thấy hiệu quả rõ rệt.

\subsection{Về Phương pháp và hình thức đánh giá}

Cần coi trọng đánh giá cả quá trình, phối hợp hợp lý và đa dạng các phương pháp và hình thức đánh giá bao gồm: đánh giá ngay trong quá trình học với các hoạt động trên lớp (quan sát thái độ, tinh thần học tập; phân tích các sản phẩm: câu trả lời, cách lập luận để đi đến đáp số, cách giải bài toán, cách sử dụng kiến thức toán trong hoạt động vui chơi... Ngoài ra, cần đánh giá bằng việc kiểm soát các hoạt động vận dụng kiến thức toán khi giải quyết vấn đề; kỹ năng sử dụng ngôn ngữ 
toán học; kỹ năng suy luận; kỹ năng kết nối các tri thức và kinh nghiệm thực tiễn vào tiếp thu các kiến thức toán học...). Chẳng hạn: quan sát học sinh sử dụng tri thức về phân số bằng nhau để giải quyết các tình huống trò chơi "Nối các phân số thích hợp" giữa hai cột đã cho; đánh giá bằng việc tìm hiểu các bài giải hay và những bài giải sai bất hợp lý, đánh giá với các dạng câu hỏi mở (có nhiều kết quả phù hợp...) để tạo cơ hội cho người học tư duy độc lập, tư duy phản biện...

\subsection{Về việc lên lớp hay ở lại của các học sinh chua đạt chuẩn}

Điểm băn khoăn lớn nhất của nhiều giáo viên là: nếu đánh giá thực chất mà có những học sinh chưa đạt chuẩn theo chương trình giáo dục các môn học thì được lên lớp hay ở lại? Việc cho học sinh ở lại lớp thì giáo viên có bị ảnh hưởng về thi đua hay không? Thực chất các băn khoăn lo lắng trên vẫn theo xu hướng cũ (bệnh thành tích) mà chưa vì sự tiến bộ và quyền lợi của người học. Câu trả lời tốt nhất mà chúng tôi tìm thấy trong cách giải quyết của các giáo viên tiểu học ở Pháp là: cung cấp đầy đủ chính xác về năng lực học tập, về phẩm chất của học sinh cho phụ huynh và tư vấn để họ tự quyết định một trong các hướng sau: xin cho con được học lại (đây là một hướng đảm bảo quyền lợi chính đáng của học sinh) hoặc xin chuyển trường với hy vọng ở môi trường mới sẽ có những biến chuyển tích cực về tâm lý giúp cho học sinh đạt kết quả tốt hơn, hoặc xin học tiếp lên lớp trên và gia đình tự chịu trách nhiệm, đảm bảo các yêu cầu về việc học tập tiếp theo của con.

Đối với các bậc phụ huynh không đủ khả năng để quyết định các vấn đề nêu trên thì hội đồng giáo dục của trường xem xét để giải quyết theo hướng đảm bảo quyền lợi phổ cập học đường của học sinh tiểu học và đảm bảo yêu cầu về chất lượng giáo dục.

\section{TÀI LIỆ THAM KHẢO}

1. Đặng Tự Ân - Nguyên Phó vụ trưởng Vụ Tiểu học (5/2013 tại Tam Đảo), Báo cáo triển khai mô hình trường họ mới VNEN tại Việt Nam.

2. Nguyễn Công Khanh (8/2014 tại Hà Nội), "Đổi mới kiểm tra đánh giá học sinh phổ thông theo cách tiếp cận năng lực", Hội thảo quốc gia về xây dụng chương trình giáp dục phồ thông.

3. Trần Ngọc Lan, Đề cuoong bài giảng chuyên đề tuơng đương: "Về kỹ thuật viết các dạng câu trắc nghiệm và ra đề kiểm tra đánh giá kết quả học tập môn Toán ở tiểu học”.

4. Lê Tiến Thành - Nguyên Vụ trưởng Vụ Tiểu học (tháng 5/2013 tại Tam Đảo), Báo cáo định hương nâng cao năng lục quản lý lớp học trong mô hình truờng học mới VNEN.

5. Tài liệu hội thảo (lưu hành nội bộ 12/2014), Xây dưng chuoong trình giáo dục phổ thông theo định huớng phát triển năng lục học sinh. 